\title{
A019 Non-invasive characterisation of road subgrade with towed-array capacitive resistivity imaging
}

O. KURAS, P. I. MELDRUM, D. BEAMISH, R. D. OGILVY British Geological Survey, Electrical Tomography Service, Keyworth, Nottingham NG12 5GG, United Kingdom

\begin{abstract}
Summary
A towed-array Capacitive Resistivity Imaging (CRI) system has been used in a controlled experiment to acquire multi-channel high-resolution ERT data on an asphalt road. Results from a CRI survey on a purpose-built trial road are discussed and compared to corresponding GPR profile data. It is demonstrated that CRI is particularly effective for the assessment of road subgrade condition. The technique is found to be sensitive to variations in moisture content and porosity in the subgrade layer, which can be used to distinguish areas of structural weakness in roadbeds. We conclude that CRI can be a valuable tool in pavement engineering as it provides complementary information to existing non-destructive testing techniques.
\end{abstract}

\section{Introduction}

Areas of sub-standard foundation beneath highways result in increased expense for road maintenance and repair and cause concern for the safety of vehicles. Road operators are therefore interested in investigative techniques that provide accurate information about the properties of the subgrade and capping layers of highway pavements. Electrical Resistivity Tomography (ERT) can provide suitable data, but is not normally applicable to the routine non-destructive testing of pavements as the difficulty of establishing galvanic contact usually precludes operation on highly resistive surface materials such as asphalt or concrete. However, recent research undertaken by BGS has confirmed that the capacitive measurement of resistivity, which overcomes the problem of galvanic contact, is equivalent to the DC technique if quasi-static conditions are maintained (Kuras, 2003; Kuras, 2002). As a consequence, electrical tomography can now be applied to pavement evaluation problems which have so far been the reserve of Ground Penetrating Radar. In the present study, we describe a controlled experiment to assess the utility of CRI for the structural evaluation and non-destructive testing of highway pavements.

\section{Description of test site and experimental procedure}

We have used a prototype towed-array CRI system developed by BGS (Beamish et al., 2001; Figure 1) to acquire multi-channel high-resolution ERT data on a purpose-built asphalt trial road at the Transport Research Laboratory in Crowthorne, Berkshire (UK). The trial road comprises a range of different subgrade materials which have been placed at different moisture contents and are designed to represent varying strength of support. The road design is based upon the UK specifications for a heavily trafficked motorway and includes a flexible asphalt pavement and compacted granular sub-base overlying the subgrade layer. The total thickness of the engineered layers is approximately $1.20 \mathrm{~m}$.

Near Surface 2004 - 10th European Meeting of Environmental and Engineering Geophysics, Utrecht, The Netherlands 
Three commonly used material types (sand, chalk and clay) constitute three adjacent sections of the subgrade layer (Figure 2). Each section of the subgrade is $12 \mathrm{~m}$ in length and divided into three subsections placed at different moisture contents at the time of construction, resulting in a total of nine discrete bays of subgrade. The pavement layer is $390 \mathrm{~mm}$ thick and consists of Hot Rolled Asphalt (HRA). The thickness of the sub-base layer is between $150 \mathrm{~mm}$ and $225 \mathrm{~mm}$. The site is underlain by the Bracklesham Beds, a series of clays and marls with sandy beds, deposited in the Middle Eocene.

The CRI survey was carried out at a speed of approximately $2.5 \mathrm{~km} / \mathrm{h}$ using a Land Rover as a towing vehicle. Magnitude and phase of the complex transfer impedance were recorded on five channels with capacitive plate-wire sensors arranged in equatorial geometry (Figure 1). Dipole separations of between $0.95 \mathrm{~m}$ and $4.70 \mathrm{~m}$ were used, corresponding to a maximum median depth of investigation of approximately $1.90 \mathrm{~m}$. An operating frequency of $14.2 \mathrm{kHz}$ and injection currents of the order of $10 \mathrm{~mA}$ were employed throughout the survey. A sampling interval of $6 \mathrm{~cm}$ was achieved, resulting in a total of more than 2400 datum points for typical five-channel datasets collected over an accessible distance of nearly $32 \mathrm{~m}$.

\section{Data processing, results and interpretation}

The measured data were found to be of high quality so that no specific pre-processing was required (Figure 2). Apparent resistivities were calculated using the in-phase component of the measured transfer impedance (Kuras, 2003). Synthetic apparent resistivity profiles obtained by DC numerical modelling showed characteristic signatures of the vertical electrical contrasts presented by the boundaries between different subgrade materials. These signatures were also observed in the experimental data.

A 2D resistivity model of the trial road was obtained by conventional least-squares inversion (Loke and Barker, 1995). The specified thicknesses of the engineered layers were presented to the inversion algorithm as a-priori information, resulting in an eight-layer model with a lateral resolution of $0.25 \mathrm{~m}$. A robust $\left(\boldsymbol{\ell}_{1}\right.$-norm) constraint was employed for the inversion. The resulting model after five iterations (5.4\% RMS error) is shown in Figure 3 with the design layout of the trial road superimposed.

The pavement layers are imaged as a highly resistive surface layer with a sharp horizontal boundary below which the subgrade layer is located. Many of the boundaries between the individual subgrade bays have been reconstructed as sharp vertical resistivity contrasts in the model. Comparison with the design specifications of the trial road shows good correlation between material properties in the bays (porosity, moisture content) and the observed resistivity pattern.

The CRI data were compared to GPR profiles acquired simultaneously. It was found that sharp contrasts in resistivity are associated with changes in the reflective pattern associated with the transition between material types. Highly resistive bodies tend to correlate with strong reflectors or zones of strong disturbance. Conductive bodies correlate with "quiet" segments in the radargram.

\section{Conclusions}

We have demonstrated that CRI extends the scope of conventional ERT to the non-destructive testing of pavements. The technique provides complementary information to existing techniques such as GPR. A controlled experiment on a trial road has shown that high quality CRI data can successfully be obtained on asphalt. The results indicate that CRI is particularly effective for the non-invasive assessment of road subgrade condition as the technique was shown to be sensitive to variations in moisture content and porosity in the subgrade layer. CRI can therefore be usefully applied to the structural evaluation of pavements and may contribute to the quantification of the strength of support offered by highway foundations. 


\section{References}

Beamish, D., Meldrum, P.I., Kuras, O. and Ogilvy, R.D., 2001. A new capacitively coupled resistivity system for the electrical impedance imaging of engineered structures, Proceedings of the 7th meeting of the Environmental and Engineering Geophysical Society - European Section, Birmingham.

Kuras, O., 2002. The capacitive resistivity technique for electrical imaging of the shallow subsurface. Ph.D. Thesis, University of Nottingham.

Kuras, O., Ogilvy, R. D., Beamish, D., Meldrum P. I. and Nathanail, C. P., 2003. Capacitive Resistivity Imaging with Towed Arrays, Proceedings of the Symposium on the Application of Geophysics to Engineering and Environmental Problems, San Antonio, Texas.

Loke, M.H. and Barker, R.D., 1995. Least-squares deconvolution of apparent resistivity pseudosections. Geophysics, 60(6): 1682-1690.

\section{Figures}

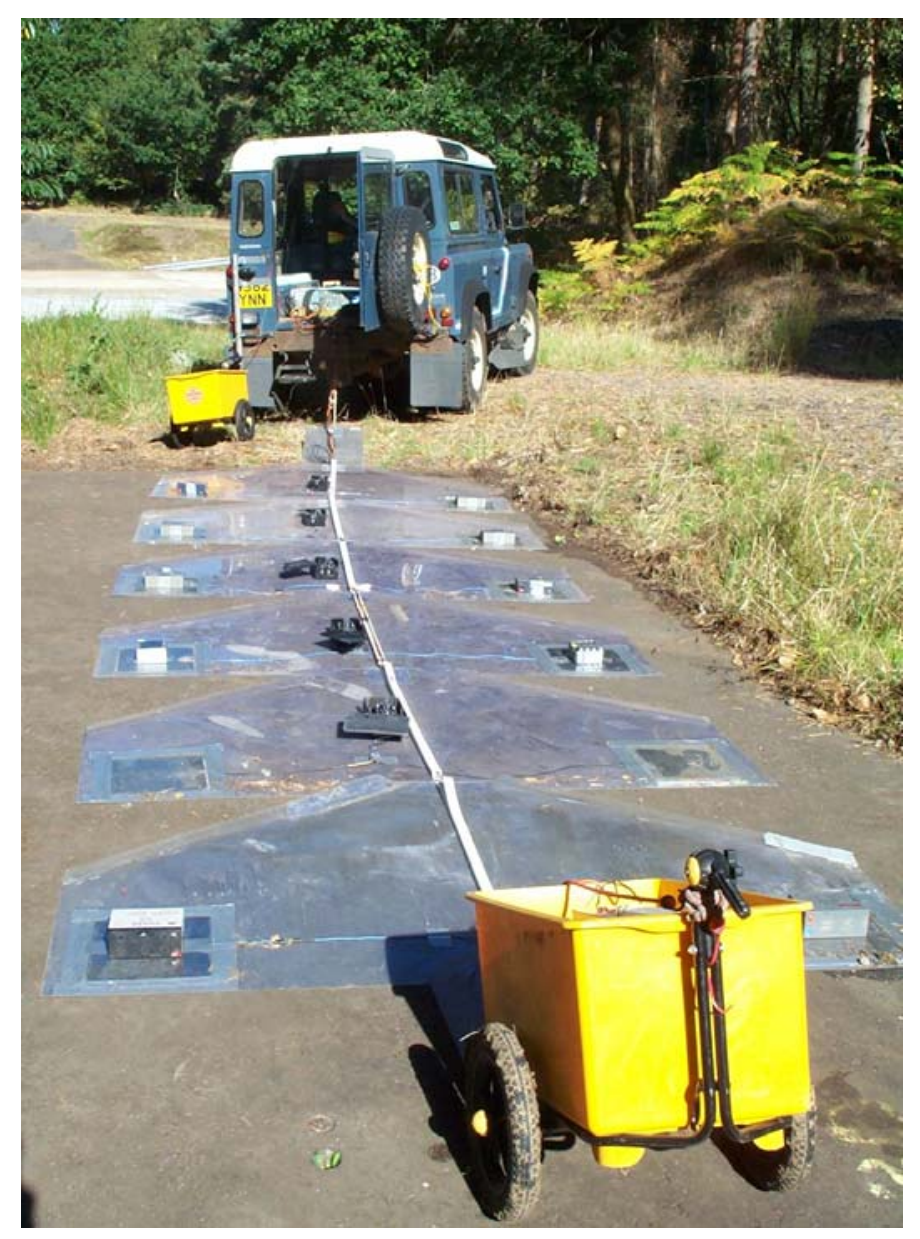

Figure 1: The BGS 5-channel towed-array prototype CRI system in field operation on the subgrade trial road at the Transport Research Laboratory. (C) NERC 2004 

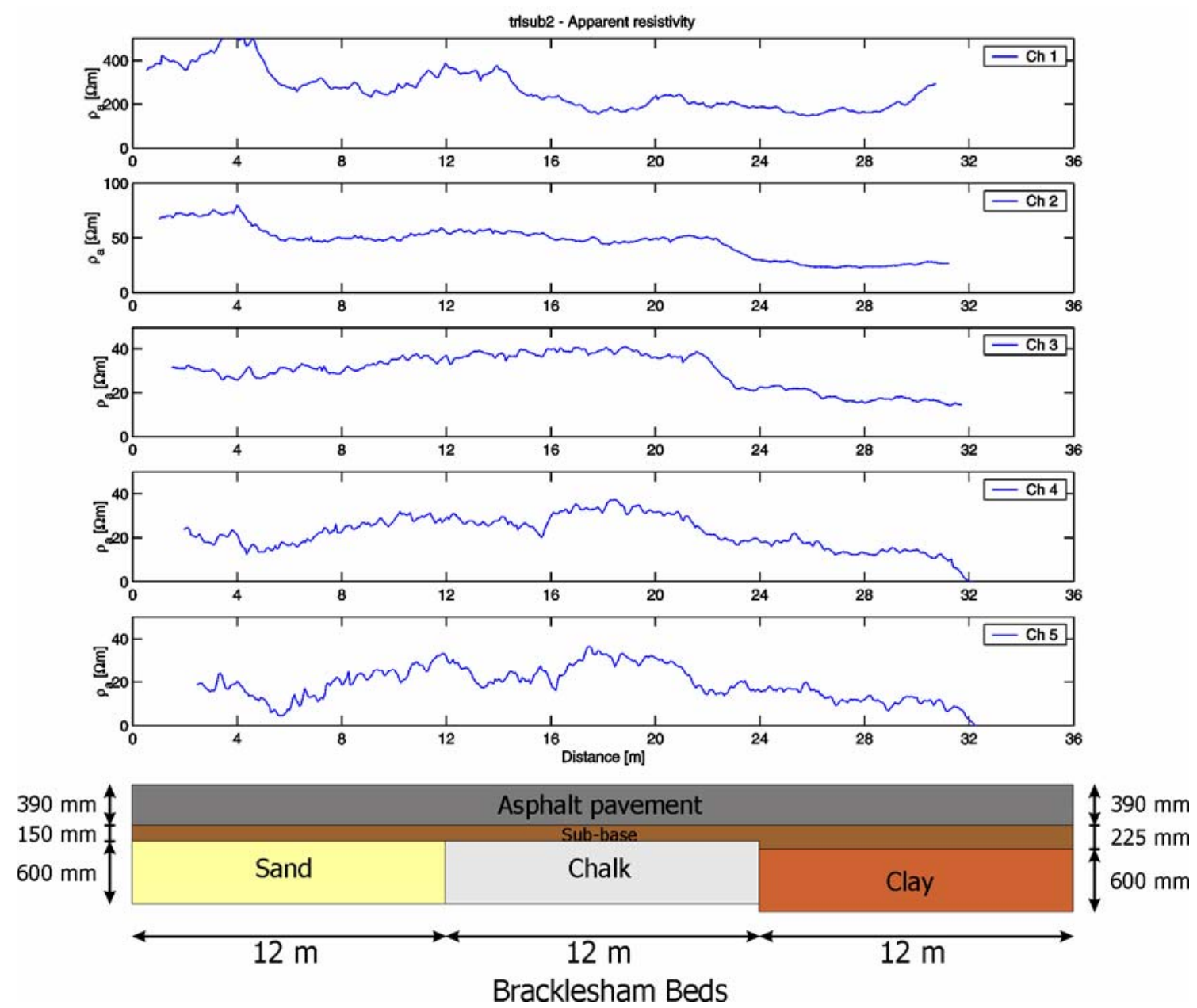

Figure 2: Design layout and constructional detail of the subgrade trial road at TRL and raw apparent resistivity data collected with the BGS CRI system.

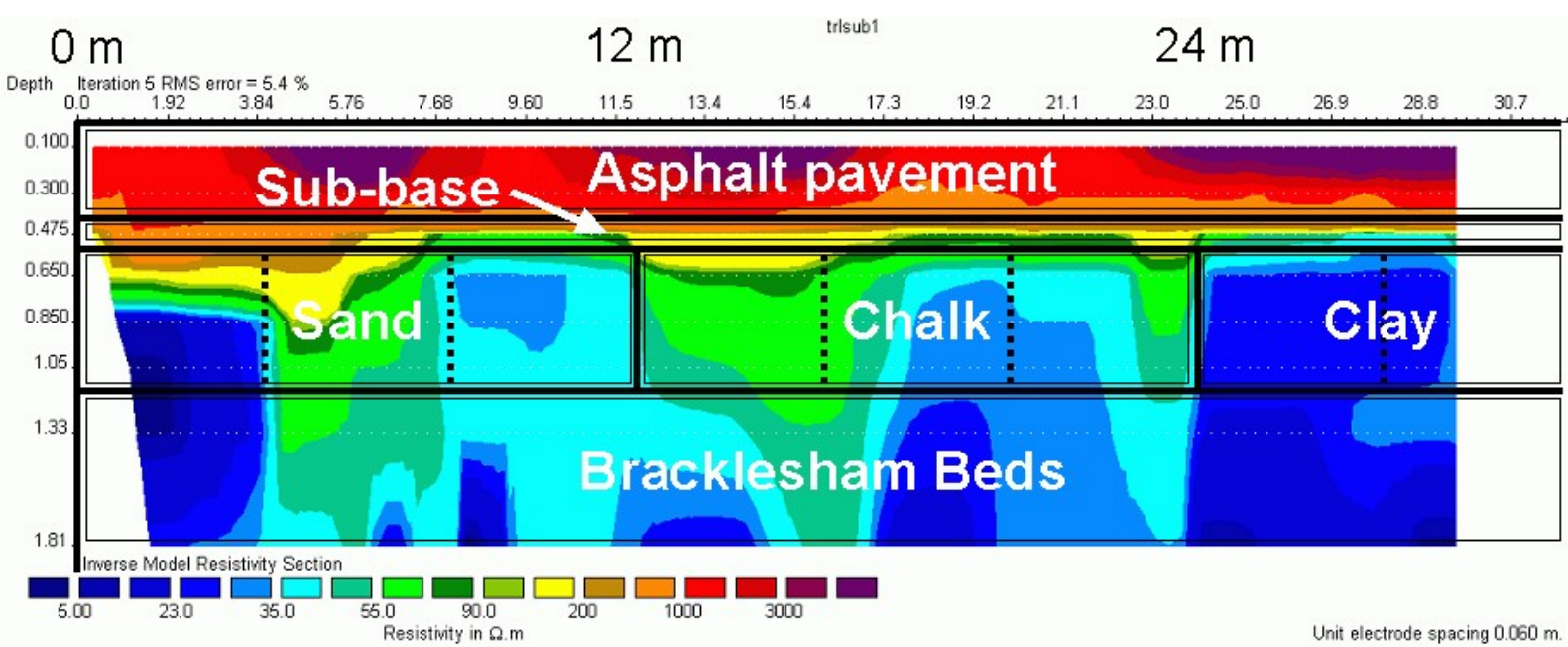

Figure 3: Resistivity model of the subgrade trial road at TRL obtained by conventional 2D inversion with a robust constraint, showing variations in electrical properties that correlate to material type, porosity and moisture content of individual subgrade bays. 